\title{
Association between anti-Müllerian hormone and other biomarkers with ovarian function in polycystic ovarian syndrome of Iraqi women
}

\author{
Huda Basim Al-Lami*, Fadhil Jawad Al-Tu'ma', and Wasan Ghazi Al-Safi²
}

'Department of Chemistry and Biochemistry, College of Medicine, University of Kerbala, Kerbala, Iraq. E. mail: fadhil.jawad@uokerbala.edu.iq; f_altoma_56@yahoo.com ${ }^{2}$ Department of Gynecology and Obstetrics, College of Medicine, University of Kerbala, Kerbala, Iraq.

*Corresponding author: Huda B. Al-Lami, Department of Chemistry and Biochemistry, College of Medicine, University of Kerbala / Kerbala-Iraq. e. mail: hudailami1993@ gmail.com

\begin{abstract}
:
Objectives: The current study aimed to investigate the role of of anti-Müllerian hormone (AMH) and other hormonal biomarkers and insulin resistance in pathogenesis of polycystic ovarian syndrome (PCOS) of Iraqi women with various ages and body mass index (BMI).

Method: The sublects include 50 cases of PCOS obtained from gynecological and obstetric teaching hospital, Kerbala health directorate/ Kerbala - Iraq and another 50 apparently healthy women as a control group. with age ranged between 18and 37 years during the period from Dec. 2019 to June, 2020 which was divided into two groups depending upon their age; first group with age (18-27) years and the second with age (28-37) years. Also, they were divided into three subgroups depending upon the BMI, normal weight $\left(18.5-24.9 \mathrm{~kg} / \mathrm{m}^{2}\right)$, overweight $\left(25-29.9 \mathrm{~kg} / \mathrm{m}^{2}\right)$, obesity $\left(30-34.9 \mathrm{~kg} / \mathrm{m}^{2}\right)$ and measurement of various hormonal levels were performed including luteinizing hormone (LH), follicle stimulating hormone (FSH), insulin, insulin resistance, total testosterone, and AMH.

Results: A significant elevated levels of each of $\mathrm{AMH}$, insulin, $\mathrm{LH}$, total testosterone, prolactin, fasting blood glucose and insulin resistance while, a non-significant differences was found in FSH levels in women with PCOS as compared with control group.

Conclusion: A significant high level of the all hormonal parameters including $\mathrm{AMH}$, $\mathrm{LH}$, prolactin and total testosterone was found in women with PCOS as compared with the control, except the FSH values.

Keyword: Anti-Müllerian hormone, Luteinizing hormone (LH), Follicle stimulating hormone (FSH) and LH/FSH ratio.
\end{abstract}

\section{Introduction}

Polycystic ovary syndrome (PCOS) is also called hyperandrogenic anovulation. It is an endocrine-metabolic disturbance which has features of multiple hormonal imbalances that produce short and long term consequences on women health. ${ }^{1}$ Polycystic ovary syndrome or Stein and Leventhal syndrome was first diagnosed in 1935. They found a series of seven cases in women suffer from amenorrhea, hirsutism, and bilateral polycystic ovaries, a condition known later as polycystic ovary syndrome (PCOS). PCOS patients clearly present a higher risk of cardiovascular diseases spatially obese PCOS patient. ${ }^{2}$ It is now categorized as the most common pathology of the endocrine system in females at reproductive age with principle features of menstrual irregularity (amenorrhea, oligomenorrhea), elevated androgens (acne, hirsuitism), and polycystic ovaries by ultrasound (Futterweit and Ryan, 2006).

In PCOS, the number of antral follicles and primary follicle pool are much higher than in healthy women and show significant correlation with serum Anti-Müllerian hormone $(\mathrm{AMH})$, which increase by $2-3$ folds, and this in combination with higher androgen level give rise to the major characteristic feature of PCOS with arrested multiple follicles of less than $10 \mathrm{~mm}$ in diameter. ${ }^{3} \mathrm{AMH}$ is considered to be a potentially important biomarker of reproductive potential of cattle. It is a growth factor, produced from the granulosa cells of ovary and sertoli cells of testes, and was first discovered to play an important role in sex differentiation in the fetal life. ${ }^{4}$

Hypersecretion of luteinizing hormone ( $\mathrm{LH})$ as the result of increased plasticity of the $\mathrm{GnRH}$, is a quite common feature of PCOS, particularly in lean women with oligoamenorrhea. ${ }^{5}$ While many women with PCOS have LH and follicle stimulating hormone (FSH) still within the $5-20 \mathrm{mIU} / \mathrm{ml}$ range, their
LH level is often two or three times than that of the FSH level. This situation is called an elevated LH/FSH ratio or a ratio of 3:1. An elevated LH/FSH ratio and increased LH responses to GnRH. ${ }^{6}$ Increased LH secretion with relatively fixed low or normal FSH secretion in women with PCOS has been first reported previously. Therefore, excess testosterone is produced primarily in the ovaries and is caused by increased LH stimulation from the pituitary and the effect of hyperinsulinemia at the ovary. ${ }^{7}$ However, increased frequency of pulsatile GnRH release that selectively increases LH secretion. ${ }^{8}$ PCOS is a diagnosis of exclusion, and prolactin levels are routinely measured in newly referred patients to exclude prolactinomas. ${ }^{9}$ High prolactin may be a marker of low dopaminergic tonus in the central nervous system. Prolactin secretion is influenced by several hormonal parameters, age, and smoking status. PCOS is associated with hyperandrogenemia and relatively high estrogen levels, which could stimulate prolactin secretion, ${ }^{10}$ also, depression and a decreased quality of life in PCOS could increase dopamine secretion and decrease prolactin levels. ${ }^{11}$

Polycystic ovarian syndrome (PCOS) is characterized as a hyperandrogenic state, the lipolytic effect of catecholamine is decreased in subcutaneous adipocytes due to low content of $\beta_{2}$-adrenoceptors and hormone sensitive lipase. It is possible that the increased testosterone levels are responsible for these abnormalities in catecholamine signal transduction in subcutaneous fat cells of PCOS women. However, in visceral fat cells of PCOS women catecholamine-induced lipolysis is enhanced which cannot be explained by testosterone. High levels of insulin in PCOS patients leads to excessive production of androgen hormone, which cause some of the unfertilized eggs to disintegrate, leading to inconsistent or nonovulation. ${ }^{12}$ The early recognition of an 'insulin resistant phenotype' is important to prevent cardiovascular involvement in a subset 
of young and susceptible PCOS patients without other signs of IR, glycemic hyperinsulinemic clamping is currently the gold-standard for measuring IR. However, it is not suitable for clinical practice since it is complex, time-consuming and not feasible in large populations. ${ }^{13}$ The association between insulin resistance and hyperandrogenism in PCOS is based mainly on two essential concepts: That insulin resistance is an important regulatory factor of ovarian synthesis of the androgens and, in the presence of hyperinsulinism, acts as a true gonadotropic hormone. ${ }^{14}$ That a condition of hyperinsulinism, occurring as a form of compensation for a state of insulin resistance, may be responsible both for an increased androgenic production and for greater values of free androgens(testosterone), by means of the reduction of hepatic synthesis of the sex hormone binding globulin SHBG. ${ }^{13}$

The presented work aimed to investigate the role of of Anti-Müllerian in the pathogenesis of PCOS of Iraqi women and its association with various body mass index (BMI), ages, insulin resistance, and other hormonal biomarkers.

\section{Materials and Methods:}

This study carried out at Research Center, Department of Biochemistry, College of Medicine, University of Kerbala and the PCOS and apparently control group individuals were obtained from Gynecological and Obstetric Teaching Hospital/Kerbala Health Directorate/Kerbala - Iraq from the period Dec. 2019 to Jul. 2020. Subjects of study involved 50 women of PCOS and another 50 healthy women with matched age range between 18 and 37 years. Women with PCOS have been checked medically by ultrasound waves to confirm that they have PCOS by radiologist. In the other hand, some women were excluded because they suffer from hypertension, pregnancy, diabetes mellitus, ischemic heart diseases, thyroid disease, pituitary tumors, women taking oral contraceptives and other hormonal drugs. Women with PCOS were diagnosed by using the Rotterdam ESHRE/ASRM criteria from 2003, that including at least two of the following: Polycystic ovaries on ultrasound, Oligo- or a ovulation, biochemical and clinical signs of hyperandrogenism. ${ }^{15}$

Blood samples are collected through a vein puncture during the follicular phase of the menstrual cycle at 9 am, and the blood sample is drawn for both patients and controls. The samples were placed in gel tubes and left for $15 \mathrm{~min}$ to clot at room temperature, then the serum was centrifuged at 3000 rpm for $15 \mathrm{~min}$. The serum was divided into Eppendorf tubes and the serial number was given in the name for each sample of samples. It was stored in the freezer at $-4{ }^{\circ} \mathrm{C}$ until it was used to measure serological tests that included measuring the level of the AMH, LH, FSH, testosterone (TT), concentration prolactin hormone (PRL) and insulin hormone concentration (IN). Each of these hormones is measured using the ELISA technique test for two monoclonal antibodies, ${ }^{16}$ based on the quantitative sandwich principle according to the manufacturer's instructions (Mannheim, Germany). The blood sugar level measured was determined by enzymatic colorimetric (GODPAP) method, using kit supplied by Spinreact, Spain.

Data were analyzed by $t$-test using SPSS version 23 statistic program the comparisons between means were made using least significant differences (LSD) using Genstat3statistic program. The difference were considered to be significant at $p<0.05$ using multivariate model in SPSS. The data are presented as mean \pm S.D (standard division). The correlation coefficient Pearson was calculated to examine association among parameters. ${ }^{17}$

\section{Results:}

The current study was conducted with the aim of studying the measurement of sexual hormones and some biochemical variables in women with PCOS in Karbala Province:Iraq. AMH levels in patients with POCS of normal weight, overweight and obesity groups were $8.05 \pm 1.11 \mathrm{ng} / \mathrm{mL}, 8.06 \pm 1.17 \mathrm{ng} /$ $\mathrm{mL}$, and $7.78 \pm 1.17 \mathrm{ng} / \mathrm{mL}$, respectively, which were increased significantly $(p<0.05)$ when compared with control group of normal weight, over weight, and obesity $(2.19 \pm 0.67 \mathrm{ng} / \mathrm{mL})$, $(2.38 \pm 0.62 \mathrm{ng} / \mathrm{mL})$ and $(2.46 \pm 0.37 \mathrm{ng} / \mathrm{mL})$ groups, respectively, as shown in Figure 1 and Table 1.

The concentration of LH was increased significantly ( $p$ $<0.05)$ in PCOS patients of first age group $(14.96 \pm 2.86 \mathrm{~m} . \mathrm{lU} /$ $\mathrm{mL})$ and second age group $(15.35 \pm 4.76 \mathrm{~m} .1 \mathrm{U} / \mathrm{mL})$ as compared with control group of first age group $(3.89 \pm 1.19 \mathrm{~m} . \mathrm{lU} /$ $\mathrm{mL})$ and second age group $(4.48 \pm 1.29 \mathrm{~m} .1 \mathrm{U} / \mathrm{mL})$, respectively (Figure 2).

The FSH concentration of women patients with POCS in first $(4.87 \pm 0.82 \mathrm{~m} . \mathrm{lU} / \mathrm{mL})$ and second $(4.44 \pm 1.22 \mathrm{~m} . \mathrm{lU} /$ $\mathrm{mL})$ age group was non-significantly different $(p<0.05)$ as compared with control group of first age $(4.86 \pm 0.94 \mathrm{~m} . \mathrm{lU} /$ $\mathrm{mL})$ and second age group $(5.09 \pm 0.48 \mathrm{~m} .1 \mathrm{U} / \mathrm{mL})$, respectively (Figure 3).

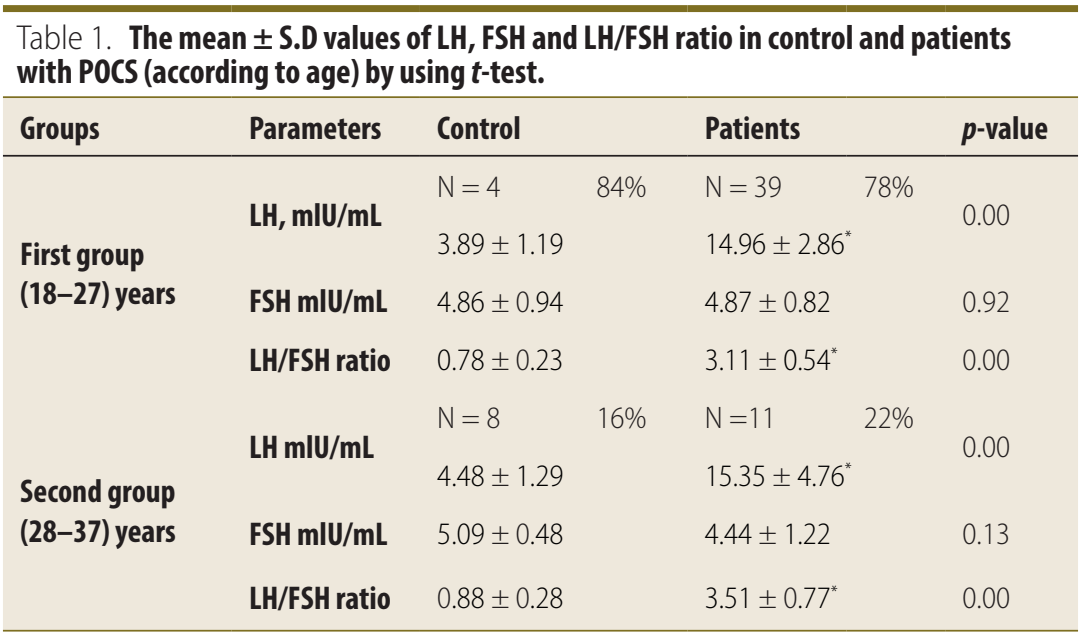




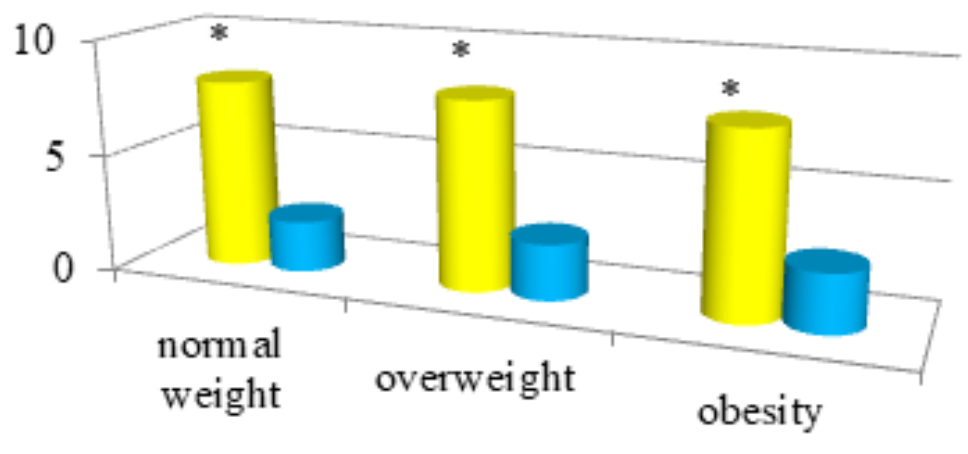

patients

control

Fig. 1 The concentration of AMH in control and PCOS patients.

${ }^{*}$ significant between control and patients at the $(p<0.05)$

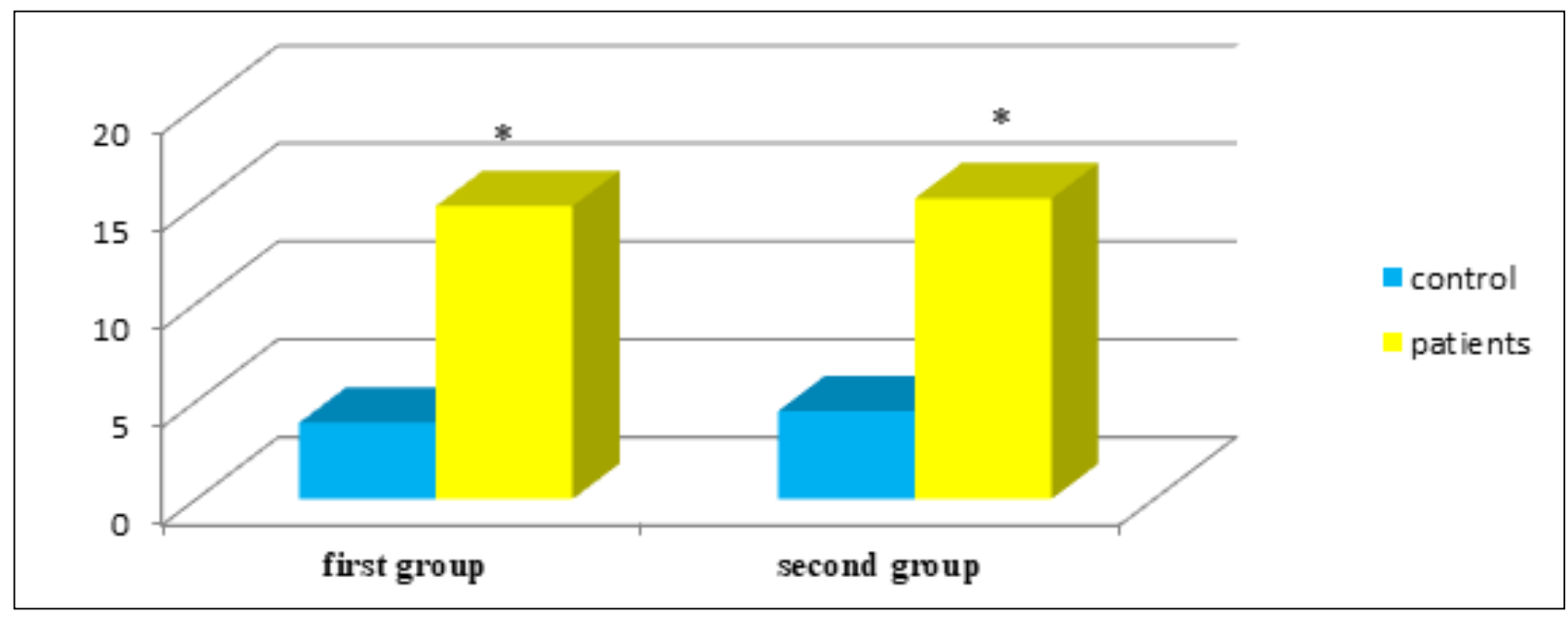

Fig. 2 The LH concentration in control and PCOS patients.

*significant between control and patients at the $(p<0.05)$

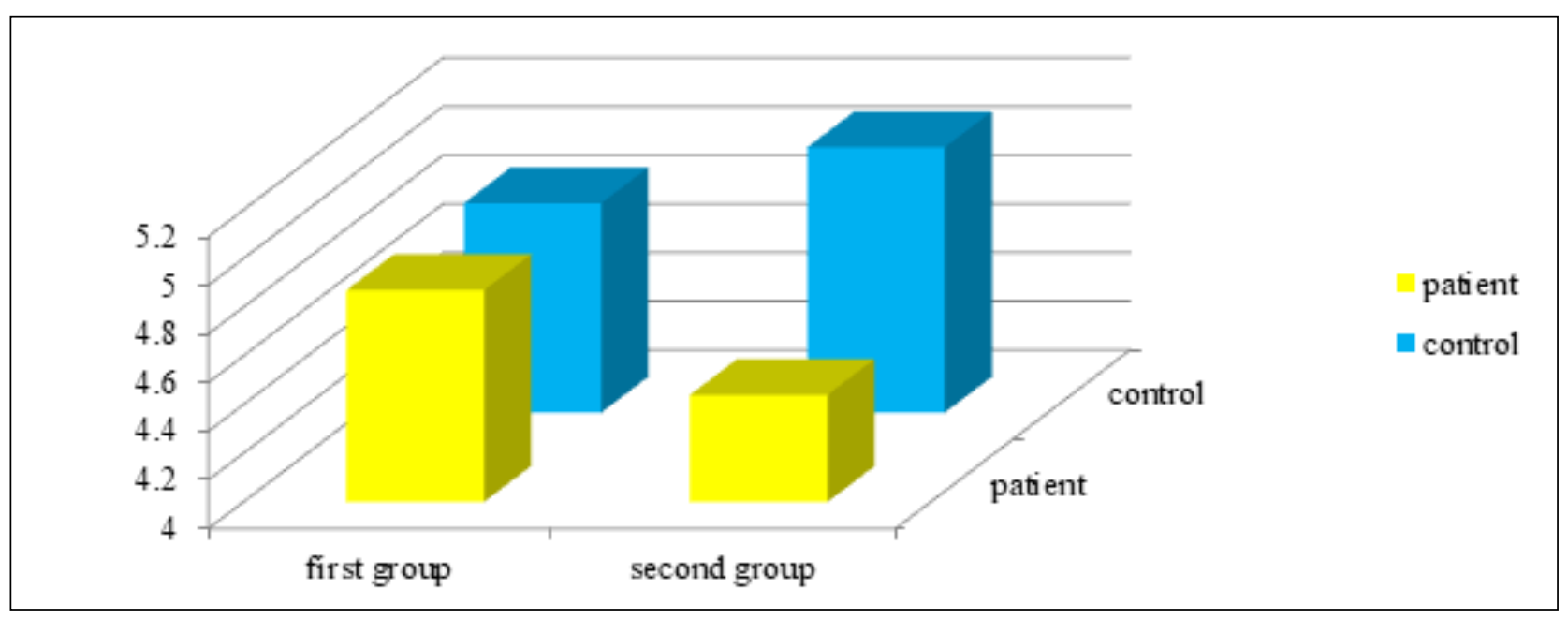

Fig. 3 Mean \pm SD of serum concentration of FSH in control and PCOS patients. 
The values of PRL was increased significantly $(p<0.05)$ in patients women with POCS of first age group $(24.86 \pm 4.92 \mathrm{ng} /$ $\mathrm{mL})$ and second age group $(20.50 \pm 4.22 \mathrm{ng} / \mathrm{mL})$ as compared with control of first age group $(17.51 \pm 5.95 \mathrm{ng} / \mathrm{mL})$ and second age group $(14.17 \pm 7.90 \mathrm{ng} / \mathrm{mL})$, respectively, see Table 2 and Figure 4 .

The values of TT observed was increased significantly $(p<0.05)$ in patients women with POCS of first age group $(0.73 \pm 0.49 \mathrm{ng} \mathrm{ng} / \mathrm{mL})$ and second age group $(0.55 \pm 0.45 \mathrm{ng} / \mathrm{mL})$ as compared with control of first age group $(0.22 \pm 0.12 \mathrm{ng} / \mathrm{mL})$ and second age group $(0.30 \pm 0.19 \mathrm{ng} / \mathrm{mL})$, respectively (Figure 5$)$.

The values of IN was increased significantly $(p<0.05)$ in patients women with POCS of first age group (17.97 \pm 0.78 $\mu \mathrm{IU} / \mathrm{mL})$ and second age group $(17.61 \pm 0.95 \mu \mathrm{IU} / \mathrm{mL}) \mathrm{com}$ pared with control of first age group $(11.56 \pm 0.78 \mu \mathrm{IU} / \mathrm{mL})$ and second age group $(12.02 \pm 0.46 \mu \mathrm{IU} / \mathrm{mL})$, respectively (Figure 6).

Insulin resistance or homeostatic model assessment (HOMA-IR) is a technique that calculate insulin resistance and $\beta$-cell function. Software program was used to solve the equations, so that the estimation of insulin resistance and $\beta$-cell function by using fasting glucose and insulin concentration as indicated in the following equation: ${ }^{18}$

\section{HOMA - IR $=[$ Glucose $(\mathbf{m g} / \mathbf{d l}) \times \operatorname{Insulin}(\mathrm{U} / \mathrm{ml})] / 405$}

The HOMA-IR observed was increased significantly $(p<0.05)$ in patients women with POCS of first age group $(4.22 \pm 0.36 \mu \mathrm{IU} /$ $\mathrm{mL})$ and second age group $(4.08 \pm 0.40 \mu \mathrm{IU} / \mathrm{mL})$ as compared with control of first age group $(2.38 \pm 0.22 \mu \mathrm{IU} / \mathrm{mL})$ and second age group $(2.43 \pm 0.06 \mu \mathrm{IU} / \mathrm{mL}$ ), respectively (Figure 7 ).

The vales of fasting blood glucose (FBG) in women patients with PCOS in normal weight $(92.07 \pm 7.67 \mathrm{mg} / \mathrm{dI})$, over weight $(95.92 \pm 4.60 \mathrm{mg} / \mathrm{dI})$, and obesity $(95.58 \pm 4.79$ $\mathrm{mg} / \mathrm{dI})$ groups increased significantly $(p<0.05)$ when compared with control group of normal weight $(81.66 \pm 2.38 \mathrm{mg} /$ $\mathrm{dI})$, over weight $(84.25 \pm 4.04 \mathrm{mg} / \mathrm{dI})$ and obesity $(80.81 \pm 2.48$ $\mathrm{mg} / \mathrm{dI}$ ) groups, respectively (Figure 8 ).

Table 2. The mean \pm SD values of PRL, TT and AMH in control and patients with POCS (According to Age) by using $\boldsymbol{t}$-test.

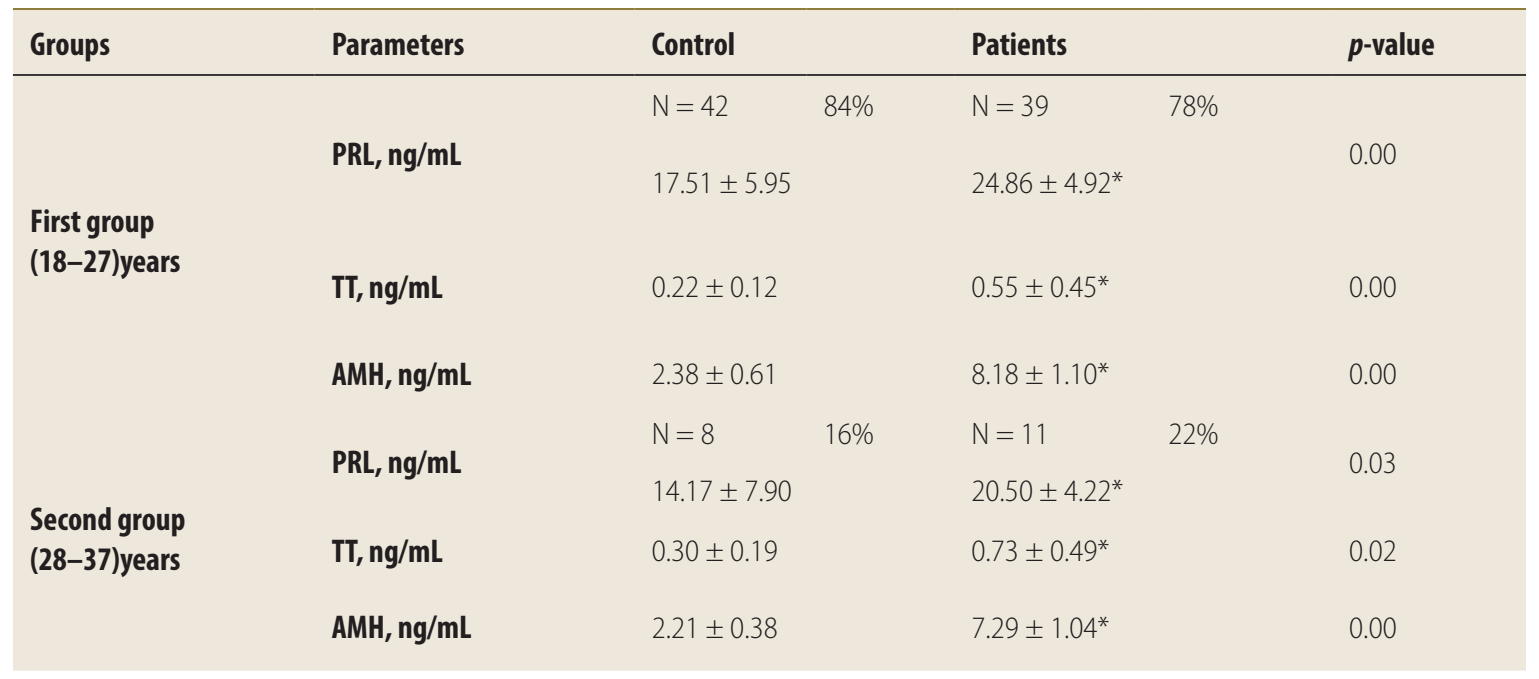

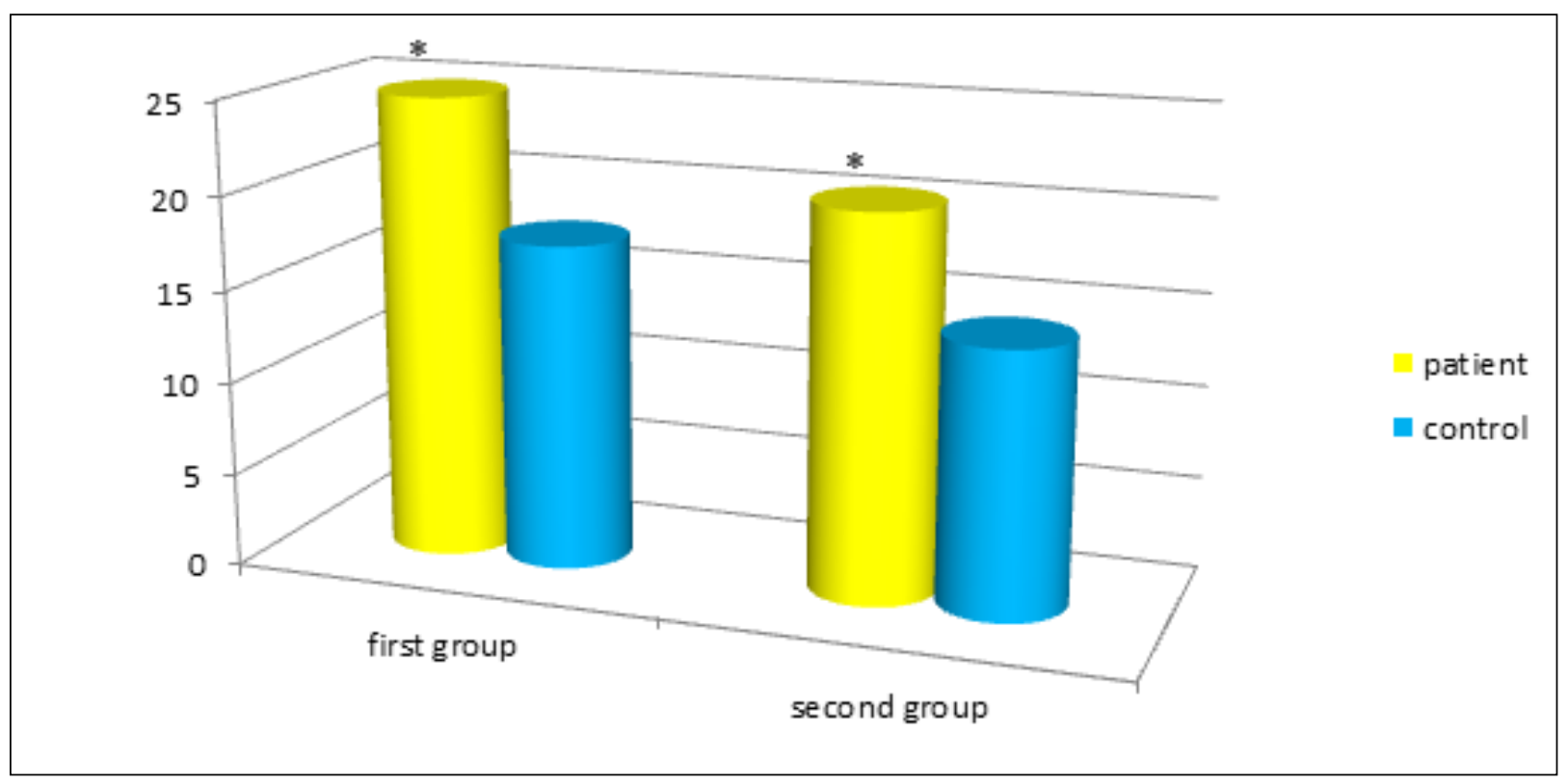

Fig. 4 The concentration of PRL in control and PCOS patients.

${ }^{*}$ significant between control and patients at the $(p<0.05)$ 


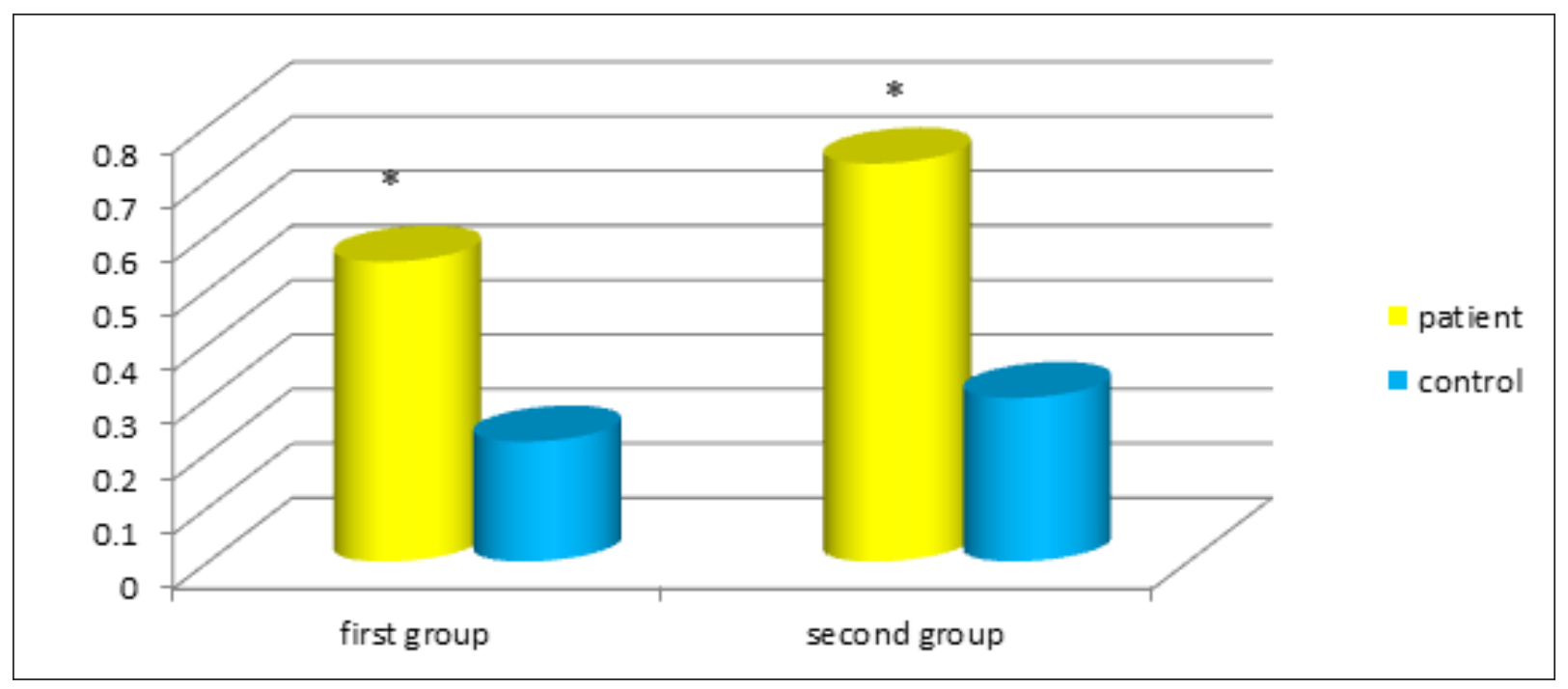

Fig. 5 The concentration of TT in control and PCOS patients.

*significant between control and patients at the $(p<0.05)$

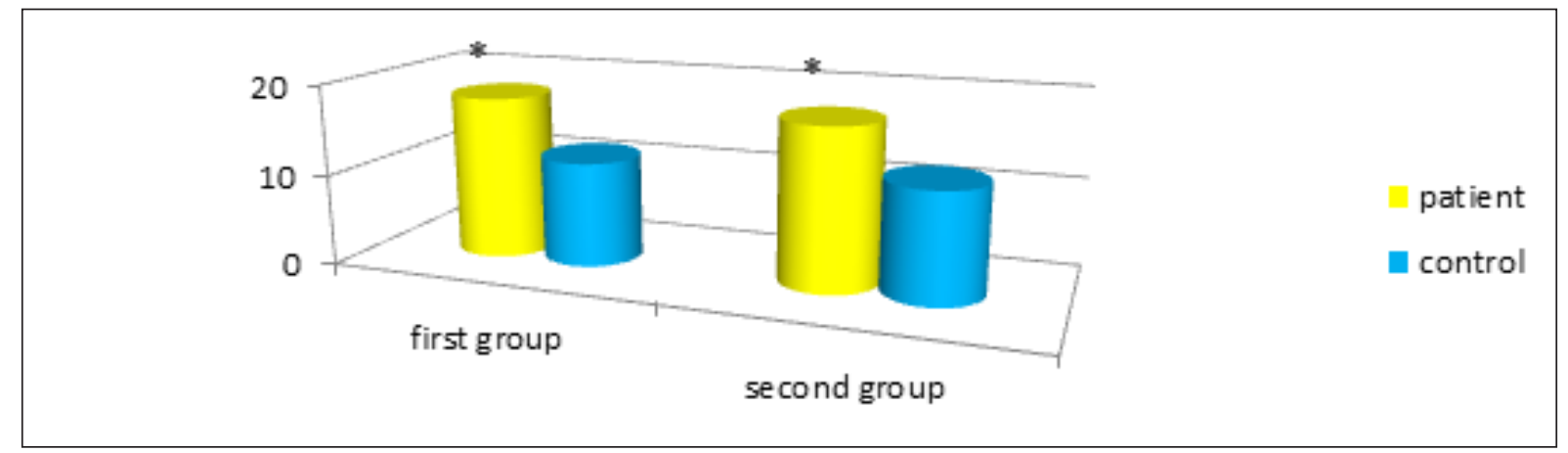

Fig. 6 The concentration of IN in control and PCOS patients.

${ }^{*}$ significant between control and patients at the $(p<0.05)$

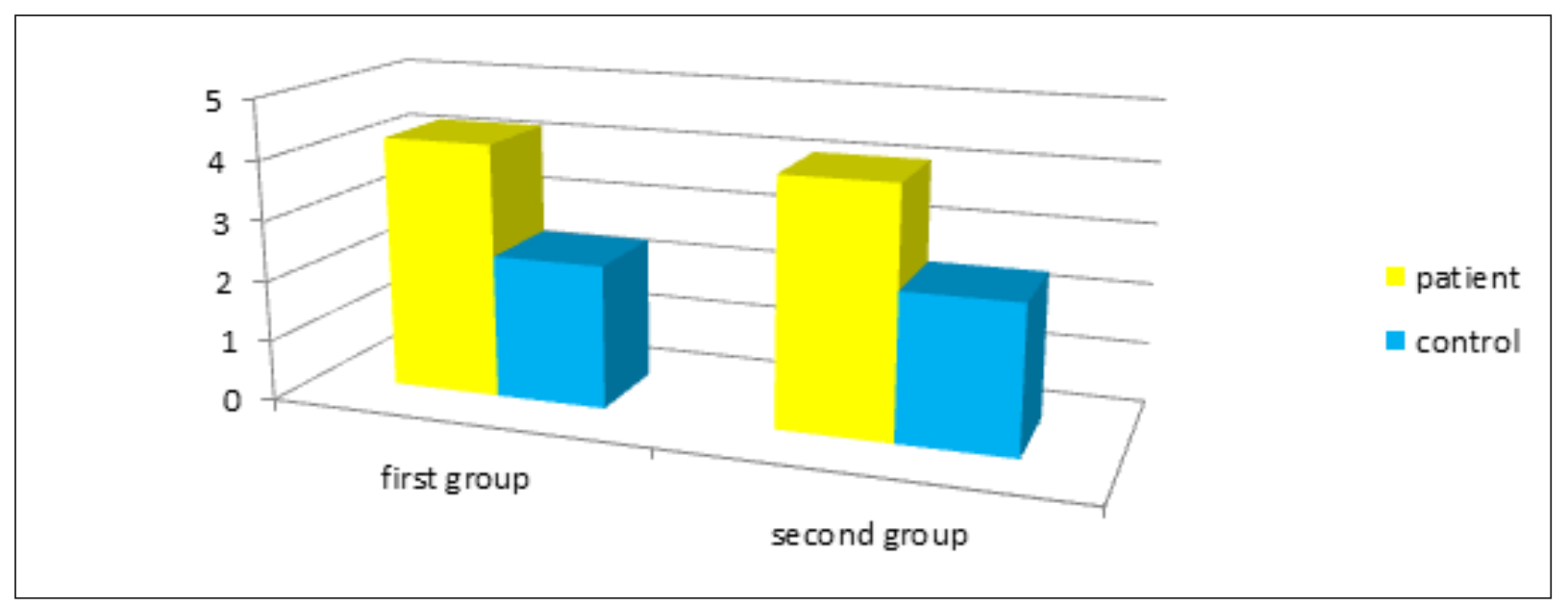

Fig. 7 The values of HOMA IR in control and PCOS patients.

${ }^{*}$ significant between control and patients at the $(p<0.05)$ 


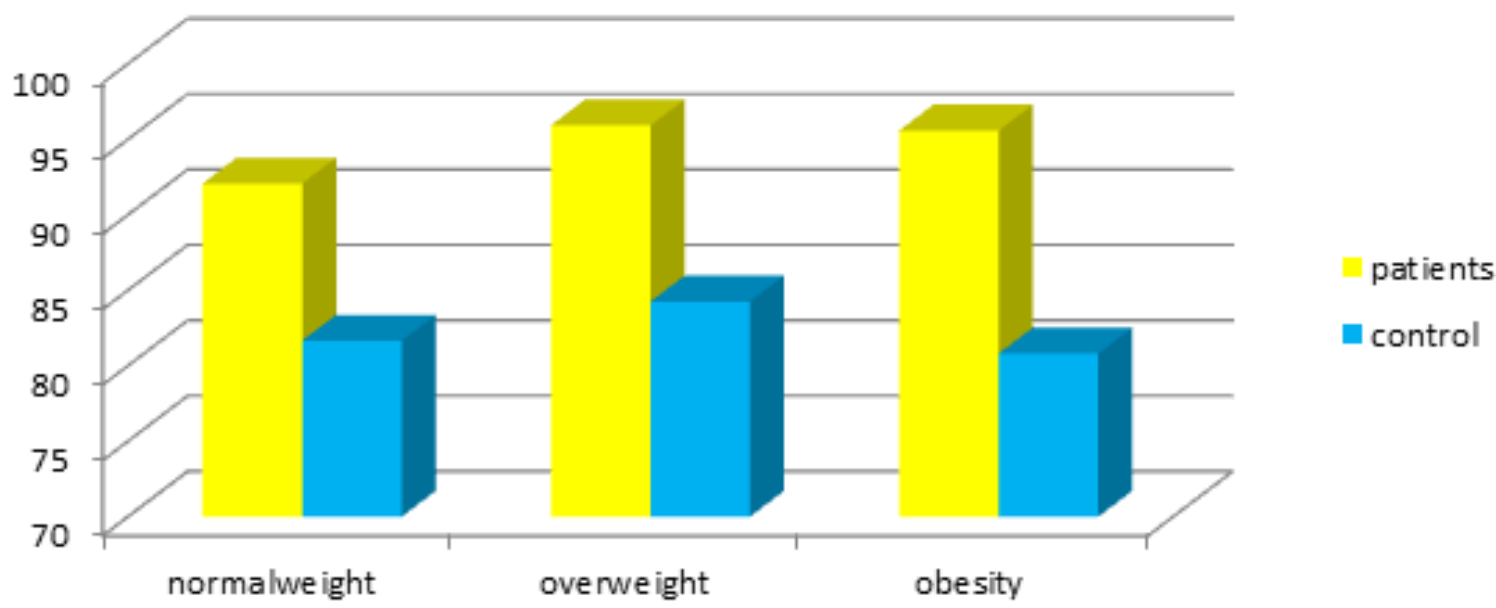

Fig. 8 The concentration of FBG in control and PCOS patients.

${ }^{*}$ significant between control and patients at the $(p<0.05)$

\section{Discussion:}

PCOS is one of the most common endocrine disorders in women of reproductive age, characterized by the growth of many follicles instead of one follicle, but these follicles fail to mature. Various biomarkers including hormonal and genetic polymorphisms have been performed in PCOS patients of Iraqi women as reported by Al-Tu'ma et al..$^{19}$ The data obtained from the present work showed that PCOS was increased in first age group with age 18-27 years, while decreased in second age group with age 28-37 years. This results due to the menstrual cycle tended for normalization with age because of decrease in the follicle population. Our result was in agreement with other study which reported the prevalence of PCOS seems to decrease with age. ${ }^{20}$ Several other studies, have reported that menstrual cycle a tended for normalization with age, mainly in those women older than 30 years (Teede et al., 2018). Thus, the ovulatory function seems to improve in PCOS patients with advancing age as a consequence of the decrease in the follicle population.

The results concerning FBG showed a significantly increase levels in women with POCS groups as compared with control. This result due to insulin resistance causing raised levels of blood glucose, which, sent to liver, than, the glucose is converted into fat and stored in the body, leading to weight gain and finally, obesity that is a key factor in creating PCOS. These results was agreement with $\mathrm{Al}-\mathrm{Auqbi},{ }^{21}$ which found increased FBG in PCOS women and about $20-28 \%$ of PCOS women were prediabetic or diabetic due to insulin resistance and PCOS women are at higher risk to develop type 2 diabetes mellitus, gestational diabetes at the reproductive age and even after age of 40 and post menopause. In PCOS, women initially glucose metabolism are normal, the rate of conversion to abnormal glucose metabolism can be $25 \%$ over just 3 years. Women with PCOS were commonly obese or overweight impaired glucose tolerance (IGT) and increased risk of type II diabetes compared to obese women. ${ }^{22}$

The LH levels was increased significantly in PCOS women as compared with control group, while no significant difference was observed regarding the FSH levels when compare between PCOS and control groups. These results was agreed with another study performed by Al-Hashimy et $\mathrm{al},{ }^{23}$ which use
PCOS women in reproductive age and they found an increased in $\mathrm{LH}$ and $\mathrm{LH} / \mathrm{FSH}$ ratio values in PCOS women while no significant difference was found in FSH values. Al-Mahdawi et al..$^{24}$ reported that $60-70 \%$ of patients with PCOS had an increase in their LH level due to increase of pulse frequency, or episodic secretion of LH. The high level of LH causes increased LH/FSH ratio in PCOS women groups as compared with control which was agreed with another study found an increased in LH/FSH ratio in women with PCOS as compared with control which may be due to primary central disorders involving GnRH secretion or secondary pituitary sensitization to $\mathrm{GnRH}$ by an abnormal feedback signals from ovaries. ${ }^{25}$ In another study on women with PCOS in reproductive age found that the ratio of LH/FSH is elevated in women with PCOS. ${ }^{26}$

There was no significant difference in FSH hormone levels reported in this study between PCOS and control. This result was agreed with another study done by Salehpour et $\mathrm{al}^{27}$ and disagreed with other study performed by Dewailly et al, ${ }^{28}$ which showed that serum LH and LH/FSH ratios were higher in women with PCOS than controls. The level of LH and LH/ FSH ratio increased significantly in PCOS women in normal weight, overweight, and obesity groups, while no significant different in FSH level in overweight and obesity but increase in PCOS of normal weight.

Results of current study was also agreed with Kamran et $\mathrm{al},{ }^{29}$ which observed that circulating $\mathrm{LH}$ and $\mathrm{LH} / \mathrm{FSH}$ ratio increased significantly in normal weight PCOS women. The occurrence of the disorder in the LH and FSH hormones is the result of hypothalamus pituitary gland, which causes the difference in the level of these hormones in the affected women. Al-Hashimy et al. ${ }^{23}$ found that $20 \%$ of women with PCOS did not change with FSH concentration.

PRL levels was increased significantly in PCOS women groups of normal weight and overweight groups which may be due to the PCOS pathogenesis related to deficient hypothalamic dopaminergic activity which is also responsible for elevated LH/ FSH ratio. These data were agreed with another studies and may refer to pituitary gland disorders. ${ }^{30}$ These data may be due to psychological and neurological disorder in women associated with this syndrome, for example, the anxious (anxiety), and this anxiety may be a main factor of PRL elevation that explains the 
progressive of increasing level of this hormone of the PCOS women's beside the other factors. Hyperprolactinemia was associated luteal phase dysfunction and may reflect the suppressive effect on elevated prolactin, due to high level of PRL blocks binding of FSH to FSH receptor on granulosa cell leading to the suppression of progesterone production. ${ }^{31}$

TT levels was increased significantly in PCOS women as compared with the control. Testosterone is one of the most common androgen used as biomarker of hyperandrogenemia in women that cause PCOS produced from the ovaries and adrenal glands in women. ${ }^{32}$ Increased LH in PCOS leads to an increase in testosterone production by the theca cells within the ovary. Women with PCOS exhibited a significantly higher TT level, than women without PCOS, which is similar to the current study. ${ }^{33}$ These results were also agreed with previous study done by Jumaa and Saood, ${ }^{34}$ which shows that women with PCOS raised serum total testosterone.

The results of the present study revealed that the AMH level is higher in PCOS in comparing with control group, which were due to excessive amount of small antral follicles in the ovaries. ${ }^{35} \mathrm{AMH}$ is mainly secreted exclusively by the granulosa cells of ovarian early developing follicles from preantral and small antral follicles indicating $\mathrm{AMH}$ role in folliculogenesis results may be due to increased production per granulosa cell, suggesting an intrinsic granulosa cell dysregulation in PCOS or because of impaired access of FSH to follicles. Elevated levels of the AMH in PCOS women groups were associated and related to increased number of follicles in women with PCOS agreement with Namik et al, ${ }^{36}$ which found increase levels of the AMH in PCOS women in their reproductive ages. $\mathrm{AMH}$ is a member of the transforming growth factor beta superfamily. ${ }^{37}$ In the women, it is solely produced by the granulosa cells of growing preantral and small antral ovarian follicles. Serum AMH levels may be used as a marker of ovarian reserve, representing the quantity and quality of the ovarian follicle pool..$^{38}$ Women with PCOS are known to have elevated baseline AMH levels when compared with agematched normo-ovulatory women. ${ }^{39}$

The results of the present study revealed significant negative correlation between AMH and age. This result indicates a reduction in $\mathrm{AMH}$ level with increasing age due to a decrease in the number of follicles as women aging and these data agrees with Kevenaar et al, ${ }^{40}$ which reported that circulating levels of AMH decline with age, may reflect the age-associated depletion of ovarian follicles.

The overweight and obesity was found as a common feature among PCOS women studies which was agreed with others. ${ }^{21}$ High BMI can influence both clinical and pathophysiology manifestations of PCOS. ${ }^{41,42}$ Their report indicate that PCOS women with BMI $>25 \mathrm{~kg} / \mathrm{m}^{2}$ have a marked increase level of insulin, glucose, LH, TT, and increased insulin resistance. BMI has an opposite relationship with androgen levels in men, whereas it seems to have a synergistic impact in women. The increase in fat tissue and body weight is related to the change in sex steroid equilibrium in pre-and postmenopausal women. Increased BMI may be major factor of endocrine and metabolism disorder in PCOs women and the obese and overweight PCOS women who had increased levels of TT and LH had a high prevalence of overweight/obesity in PCOS women.

Results of current study showed significant difference in serum insulin and insulin resistance (HOMA-IR), which is higher in PCOS patients as compared with control and the results were similar to studies done by others. ${ }^{43}$ Insulin resistance with hyperinsulinemia, is one causes of the pathogenesis of PCOS and it lead to development of complications related to PCOS and increased ovarian androgen production in PCOS stimulates hyperinsulinemia due to IR. ${ }^{8}$

The proposed mechanisms for insulin-reproductive abnormalities include abnormalities of ovarian steroidogenesis, excessive LH secretion and abnormalities in glucose uptake. There are three possible mechanisms have been proposed for androgen hypersecretion include: an intrinsic functional theca cell defect, hyperinsulinemia following insulin resistance and hypersecretion of pituitary LH resulting in extreme theca stimulation. ${ }^{44}$

Spritzer $^{45}$ reported that hyperinsulinemia and IR determination of hyperandrogenemia by stimulate ovarian theca cells to secrete androgens and increase the effect of LH on the production of ovarian androgens. Insulin and HOMA-IR in present study was increased significantly in PCOS women of normal weight, overweight and obesity groups. Insulin resistance is a common feature of PCOS and is more marked in obese women, suggesting that PCOS and obesity have a synergistic effect on the magnitude of the insulin disorders. ${ }^{46}$ Our results agrees with others which reported that PCOS women demonstrate greater variation in insulin parameters compared to controls, independent of weight. ${ }^{47}$ IR and hyperinsulinemia can be caused by obesity with visceral fat accumulation; hyperinsulinemia affects granulosa cells in small follicles and theca cells and this condition induces early response to LH on granulosa cells of small follicles and causes premature differentiation of these cells, which eventually results in anovulation. ${ }^{48}$ Other stuy found that obesity increases insulin resistance, and the presence of polycystic ovaries increases insulin resistance. The presence of polycystic ovaries appears to have a stronger influence than obesity on insulin resistance. ${ }^{49}$ The results obtained agree with other study found that weight gain occurs as a result of increased insulin levels and stimulates the ovaries to produce testosterone, so weight gain increase the testosterone hormone. Insulin has an inhibitory effect on hepatic production of SHBG resulting in increase of free testosterone in addition to its stimulatory effect to the ovarian androgen production augmenting the state of hyperandrogenism. ${ }^{50}$

\section{Conclusion:}

This study revealed there are significant positive correlation in LH/FSH ratio with BMI and age of PCOS women.

This study revealed there are significant negative correlation in PRL and age of PCOS women.

A significant rise in the levels of the AMH, IN, LH, TT, PRL, FBG and HOMA IR was found significantly in women with PCOS significantly compared to control, while no significant difference was found in FSH values between a group of infected women and a control group.

\section{References:}

1.Kollmann, M, Martins, WP, and Raine-Fenning, N. Terms and thresholds for the ultrasound evaluation of the ovaries in women with hyperandrogenic anovulation. Human Reprod Update, 2014;20(3):463-464.

2.Al-Tu'ma, FJ, Ahmed, NN, and Al-Safi, WG. Total antioxidant capacity and homocysteine levels in obese women with polycystic ovary syndrome. Int J Pharm Pharm Res, 2017:8:78-86.

3.Laven JS, Mulders AG, Visser JA, Themmen AP, De Jong FH, and Fauser BC. Anti-Mullerian hormone serum concentrations in normoovulatory and anovulatory women of reproductive age. J Clin Endocrinol Metab, 2004; 89(1):318-23. 
4.Lee, MM, Noto, A, Schoenfeld, DT, Maclaughlin, G, Mol, NC, and Grant ET. Substance in humans. Normal 2008:81:2-7.

5.Hendriks, ML, Brouwer, J, Hompes, PG, Homburg, R, and Lambalk, CB. LH as a diagnostic criterion for polycystic ovary syndrome in patients with WHO II oligo / amenorrhoea. Reprod Biomed Online, 2008;16(6):765-771.

6.Azziz, R. Diagnosis of polycystic ovarian syndrome: the Rotterdam criteria are premature. J Clin Endocrinol Metab, 2006;91(3):781-785.

7.Sheehan, MT. Polycystic ovarian syndrome: diagnosis and management. Clin Med Res, 2004;2(1):13-27.

8.Diamanti-Kandarakis, E, and Dunaif, A. Insulin resistance and the polycystic ovary syndrome revisited: an update on mechanisms and implications. Endocr Rev, 2012;33(6):981-1030.

9.Glintborg, D, and Andersen, M. An update on the pathogenesis, inflammation, and metabolism in hirsutism and polycystic ovary syndrome. Gynecol Endocrinol. 2010;26(4):281-296.

10. Glintborg, D, Altinok, M, Mumm, H, Buch, K, Ravn, P, and Andersen, M. Prolactin is associated with metabolic risk and cortisol in 1007 women with polycystic ovary syndrome. Human Reprod., 2014;29(8):1773-79.

11. Altinok, ML, Glintborg, D, Depont Christensen, R, Hallas, J, and Andersen, M. Prescription of antidepressants is increased in Danish patients with polycystic ovary syndrome and is associated with hyperandrogenism. A population-based cohort study. Clin Endocrinol 2014;80(6):884-889.

12. Arner, P. Effects of testosterone on fat cell lipolysis. Species differences and possible role in polycystic ovarian syndrome. Biochimie. 2005;87(1):39-43.

13. González, F. Inflammation in polycystic ovary syndrome: Underpinning of insulin resistance and ovarian dysfunction. Steroids 2012;77(4):300-305.

14. Denson, TF, Mehta, PH, and Tan, D.H. Endogenous testosterone and cortisol jointly influence reactive aggression in women. Psychoneuroendocrinology. 2016;38(3):416-424.

15. Bremer, AA, and Miller, WL. The serine phosphorylation hypothesis of polycystic ovary syndrome: A unifying mechanism for hyperandrogenemia and insulin resistance. Fertil Steril. 2008;89(5):1039-1048.

16. Nelson, SM, Iliodromiti, S, Fleming, R, Anderson, R, McConnachie, A, and Messow, C. M. Reference range for the antimüllerian hormone generation II assay: A population study of 10,984 women, with comparison to the established Diagnostics Systems Laboratory nomogram. Fertil Steril. 2014;101(2):523-529.

17. SPSS. Statistical Package for Social Science, Users Guide for Statistics. 2015.

18. Kanauchi M. A new index of insulin sensitivity obtained from the oral glucose tolerance test applicable to advanced type 2 diabetes. Diabet Care. 2002 Oct 1;25(10):1891-2.

19. Al-Tu'ma, FJ., Farhan NH, and Al-Safi, WG. Association between fat mass and obesity gene (re9939609) polymorphism with PCOS women in Iraqi poipulation. Int J Pharm Pharm Res, 2015;5(1):62-72.

20. Lauritsen, MP, Bentzen, JG, Pinborg, A, Loft, A, Forman, JL, Thuesen, LL, and Nyboe Andersen, A. The prevalence of polycystic ovary syndrome in a normal population according to the Rotterdam criteria versus revised criteria including anti-Müllerian hormone. Human Reprod. 2014;29(4):791-801.

21. AL-Auqbi, TF Obesity, glycemic and hormonal criteria of polycystic ovary syndrome. Al-Kindy Coll Med J, 2009; 5(1):33-39.

22. Kensara, OA. Prevalence of hypovitaminosis $D$, and its association with hypoadiponectinemia and hyperfollistatinemia, in Saudi women with naïve polycystic ovary syndrome. J Clin Transl Endocrinol. 2018;12:20-25.

23. Al-Hashimy, DH, Al-Rikaby, HR, and Al-Khayaat, ES. Study of some hormonal disorders associated with polycystic ovarian syndrome in women in Thi Qar Governorate. J Educ Pure Sci Univ Thi-Qar, 2019;9(2):25-31.

24. Al-Mahdawi, MA, Khadhem, HK, and Al-Jebori, SR Effect of physical activity on sex hormones in polycystic ovary syndrome Iraqi women. Iraqi J Biotechnol, 2018;17(1):98-107.

25. Hassan, BF. Measuring the concentration of some hormones in patients sera of polycystic ovaries. Baghdad Sci J. 2010;7(4):1384-1388.

26. Marbut, MM, Awwad, NY, Yousif, MN, and Ahmed, MS. Hormonal assessment in women with polycystic ovary syndrome in Tikrit city. J Madenat Alelem Univ Coll. 2019;11(1):1-9.

27. Salehpour, S, Tohidi, M, Akhound, MR, and Amirzargar, N. N acetyl cysteine, a novel remedy for poly cystic ovarian syndrome. J Fertil Steril. 2009;2:66-73.

28. Dewailly, D, Catteau-Jonard, S, Reyss, AC, Leroy, M, and Pigny, P. Oligo anovulation with polycystic ovaries but not overt hyperandrogenism. J Clin Endocrinol Metab. 2006;91(10):3922-27.

29. Kamran U, Tanzilur R, Dan-Dan W, Xian-Hua L, Ye L, Xiao-Yan G, Peter CKL, Run-Ju Z, He-Feng H and Jian-Zhong S. Concentrations are increased in association with luteinizing hormone and nesfatin-1 concentrations in women with polycystic ovary syndrome, Clin Chim Acta. 2017;471:243-247.

30. Hassan, MF. Original research the frequency of elevated prolactin level in polycystic ovary syndrome women (PCOS) and its' effect on pregnancy rate. Global J Public Health Med. 2020;2(1):109-117.

31. Porter, MB, Brumsted, JR, and Sites, CK, Effect of prolactin on folliclestimulating hormone receptor binding and progesterone production in cultured porcine granulosa cells. Fertil Steril. 2000;73(1):99-105.

32. Münzker, J, Hofer, D, Trummer, C, Ulbing, M, Harger, A, Pieber, T, and Obermayer-Pietsch, B. Testosterone to dihydrotestosterone ratio as a new biomarker for an adverse metabolic phenotype in the polycystic ovary syndrome. J Clin Endocrinol Metab. 2015;100(2):653-660.

33. Sung, $Y A, O h, J Y, C h u n g, H$, and Lee, $H$. Hyperandrogenemia is implicated in both the metabolic and reproductive morbidities of polycystic ovary syndrome. Fertil Steril. 2014;101(3):840-845.

34. Jumaa, MN and Saood, NA. Study of hormonal levels changes in women's serum with polycystic ovaries syndrome (PCOS). J Univ Anbar Pure Sci. 2011;5(1):17-23.

35. Weenen C, Laven JS, Von Bergh AR, Cranfield M, Groome NP, and Visser JA. Anti-mullerian hormone expression pattern in the human ovary: Potential implication for initial and cyclic follicle recruitment. Mol Hum Reprod. 2004;10:77-83.

36. Namik, JJ, Alalaf, SK, and Al-Tawil, N. G. Anti-Mullerian hormone and antral follicle count in polycystic ovary syndrome and non-polycystic ovary syndrome women. Zanco J Med Sci. 2018;22(3):292-299.

37. Van Rooij IA, Broekmans FJ, te Velde ER, Fauser BC, Bancsi LF, de Jong FH, et al. Serum anti-Mullerian hormone levels: a novel measure of ovarian reserve. Hum Reprod 2002;17:3065-3071

38. La Marca A, Sighinolfi G, Radi D, Argento C, Baraldi E, and Carducci Artenisio. Anti-Mullerian hormone (AMH) as a predictive marker in assisted reproductive technology (ART). Hum Reprod Update. 2010;16:113-130.

39. Piltonen T, Morin-Papunen L, Koivunen R, Perheentupa A, Ruokonen A, and Tapanainen JS. Serum anti-Mullerian hormone levels remain high until late reproductive age and decrease during metformin therapy in women with polycystic ovary syndrome. Hum Reprod. 2005;20:1820-1826.

40. Kevenaar, ME, Meerasahib, MF, Kramer, P, van de Lang-Born, BM, de Jong, $\mathrm{FH}$, Groome, NP, and Visser, JA. Serum anti-mullerian hormone levels reflect the size of the primordial follicle pool in mice. Endocrinology. 2006;147(7):3228-3234.

41. Wang, F, Dai, W, Yang, XH, Guo, YH, and Sun, YP. Analyses of optimal body mass index for infertile patients with either polycystic or non-polycystic ovary syndrome during assisted reproductive treatment in China. Sci Rep. 2016;6(1):1-9.

42. Al-Shammaa, H, El-Yassin, HD, and Shamam, KH. Serum resistin levels, and other hormonal and biochemical parameters in patients with polycystic ovary syndrome (PCOS). J Facul Med. 2009;51(2):200-203.

43. Mohammed, DQ, Hawaa, AD, and Husein, SM. Correlation between homocysteine and insulin resistance in women with polycystic ovarian syndrome referring to AL-Yarmook Teaching Hospital. Iraqi J Embryo Infertil Res. 2014;4(2):32-39.

44. Cadagan, D, Khan, R, and Amer, S. Thecal cell sensitivity to luteinizing hormone and insulin in polycystic ovarian syndrome. Reprod Biol. 2016;16(1):53-60

45. Spritzer, PM. Polycystic ovary syndrome: reviewing diagnosis and management of metabolic disturbances. Arq Brasil Endocrinol Metab. 2014;58(2):182-187

46. Nogueiras, R, Gualillo, O, Caminos, JE, Casanueva, F, and Diéguez, C. Regulation of resistin by gonadal, thyroid hormone, and nutritional status. Obesity Res. 2003;11(3):408-414.

47. Jayagopal, V, Kilpatrick, E. S, Holding, S, Jennings, P. E. and Atkin, S. L. The biological variation of insulin resistance in polycystic ovarian syndrome. J Clin Endocrinol Metab, 2002;87(4):1560-1562.

48. Sakumoto, T, Tokunaga, Y, Tanaka, H, Nohara, M, Motegi, E, Shinkawa, T, and Higashi, M. Insulin resistance/hyperinsulinemia and reproductive disorders in infertile women. Reprod Med Biol. 2010;9(4):185-190.

49. Cresswell, J, Fraser, RB, Bruce, C, Egger, P, Phillips, D, and Barker, D. J. Relationship between polycystic ovaries, body mass index and insulin resistance. Acta Obstet Gynecol Scand. 2003;82(1):61-64.

50. Temel, I, Çelik, Ö, HASÇALIK, Ş, Çelik, N, Şahin, I, and Aydin, S. Serum nonesterified fatty acids, ghrelin, and homocysteine levels in women with polycystic ovary syndrome. Turk J Med Sci. 2010;40(2):221-228. 